\title{
Simultaneous Bilateral Flexion-Type Salter-Harris II Fractures of the Proximal Tibia: A Case Report and Review of the Literature
}

\author{
V. Potenza*, R. Caterini, P. Maglione, S. Bisicchia and P. Farsetti \\ Department of Orthopaedic Surgery, University of Rome Tor Vergata, Viale Oxford 81, 00133 Rome, Italy
}

\begin{abstract}
A rare case is reported of bilateral physeal lesions of the proximal tibia classified as Salter-Harris type II, which occurred simultaneously after a "flexion type" injury in a 14-year-old boy. Treatment was conservative on the nondisplaced side and surgical, by closed reduction and internal fixation, on the displaced side. There was no previous diagnosis of Osgood-Schlatter disease. After reviewing all the cases described previously, which occurred either consecutively or simultaneously, we conclude that less resistance of the growth plate, typical of late adolescence, likely represents the cause of this type of lesion.
\end{abstract}

Keywords: Bilateral physeal fractures, proximal tibia, flexion-type.

\section{INTRODUCTION}

Proximal tibial physeal fractures are relatively rare lesions, representing less than 1 per cent of all physeal injuries [1-4]. These lesions typically occur in children and adolescents during sport activities, and in most cases are classified as type I, II or III, according to Salter-Harris. Type II injuries are frequently displaced, and generally they are caused by an abduction or adduction trauma of the knee (varus and valgus type) or by an hyperextension trauma (hyperextension type). Rarely, these injuries may be caused by a rapid flexion of the knee against the contracting quadriceps during landing (flexion type) [5-8]. To the best of our knowledge, few cases of bilateral flexion-type SalterHarris II fractures have been reported, and in most cases they occurred consecutively [9-11]. Simultaneous bilateral fractures are extremely rare [12-14]. We report a case of simultaneous bilateral flexion-type Salter-Harris II fractures of the proximal tibia, in a 14-year-old basketball player, nondisplaced on the right side and displaced on the left. He was treated conservatively on the right knee and surgically on the left, by closed reduction and percutaneous internal fixation. We have also reviewed all the cases reported previously, in order to discuss the possible causes of this type of lesion.

\section{CASE REPORT}

A 14 year-old boy fell on the ground while landing from a high jump during a basketball game. He felt immediate bilateral knee pain and was unable to stand. The physical examination, performed in the Emergency Room of our Hospital, showed bilateral anterior knee swelling, with a marked restriction of the range of motion of both knees. No neurovascular deficits were present. The patient was a welldeveloped teen-ager, who weighed $80 \mathrm{~kg}$ and was $180 \mathrm{~cm}$ tall; no previous history of trauma was reported. Anteroposterior and lateral radiographic examinations of both knees

*Address correspondence to this author at the Department of Orthopaedic Surgery, University of Rome Tor Vergata, Viale Oxford 81, 00133 Rome, Italy; Tel: +390620903466; Fax: +390620903665;

E-mail: vitopotenza2@virgilio.it showed bilateral fractures of the proximal tibial physis, classified as flexion-type Salter-Harris II, non-displaced on the right side and displaced on the left with an anterior apex.

The day after admission to our Hospital, the patient was treated in the operating room under general anaesthesia. The displaced fracture was reduced, under fluoroscopic control, by closed manipulation in hyperextension but, since it was unstable, it was fixed percutaneously by two $5 \mathrm{~mm}$ cannulated screws, introduced from the anterior tibial tubercle to the posterior metaphyseal cortex. A long-leg cast extending above the knee was applied in extension position. The same cast was applied to stabilize the non-displaced fracture, without any fixation. Both casts were left in place for six weeks without weight-bearing. X-rays of both knees, performed one week after the operation, did not show any secondary displacement of the fractures. Six weeks after surgery the casts were removed, and x-rays showed complete healing of both fractures. The patient started physical therapy and weight-bearing was allowed. At the final followup, one year after the operation, the patient had resumed playing basketball without restrictions, the range of motion of both knees was complete, and no deformity or leg-length discrepancy was present. The radiographic examination showed almost complete fusion of the proximal tibial epiphyses of both knees (Fig. 1).

\section{DISCUSSION}

Fractures of the proximal tibial physis are uncommon injuries, caused in most cases by an indirect force, which occur during sport activities [1-5]. The mechanism of injury and the type of lesion are age-dependent [5]. In childhood, the most frequent mechanism of injury is an abduction or adduction force (varus or valgus type); between 10 and 12 years of age the most frequent mechanism of injury is an hyperextension trauma of the knee which occurs during jumping (hyperextension type), whereas in late adolescence these fractures are extremely rare and are caused by a forced flexion of the knee during landing (flexion type) [5]. Most separations of the proximal tibial physis caused by a flexion trauma are classified as Salter-Harris type I, II or III. Some 


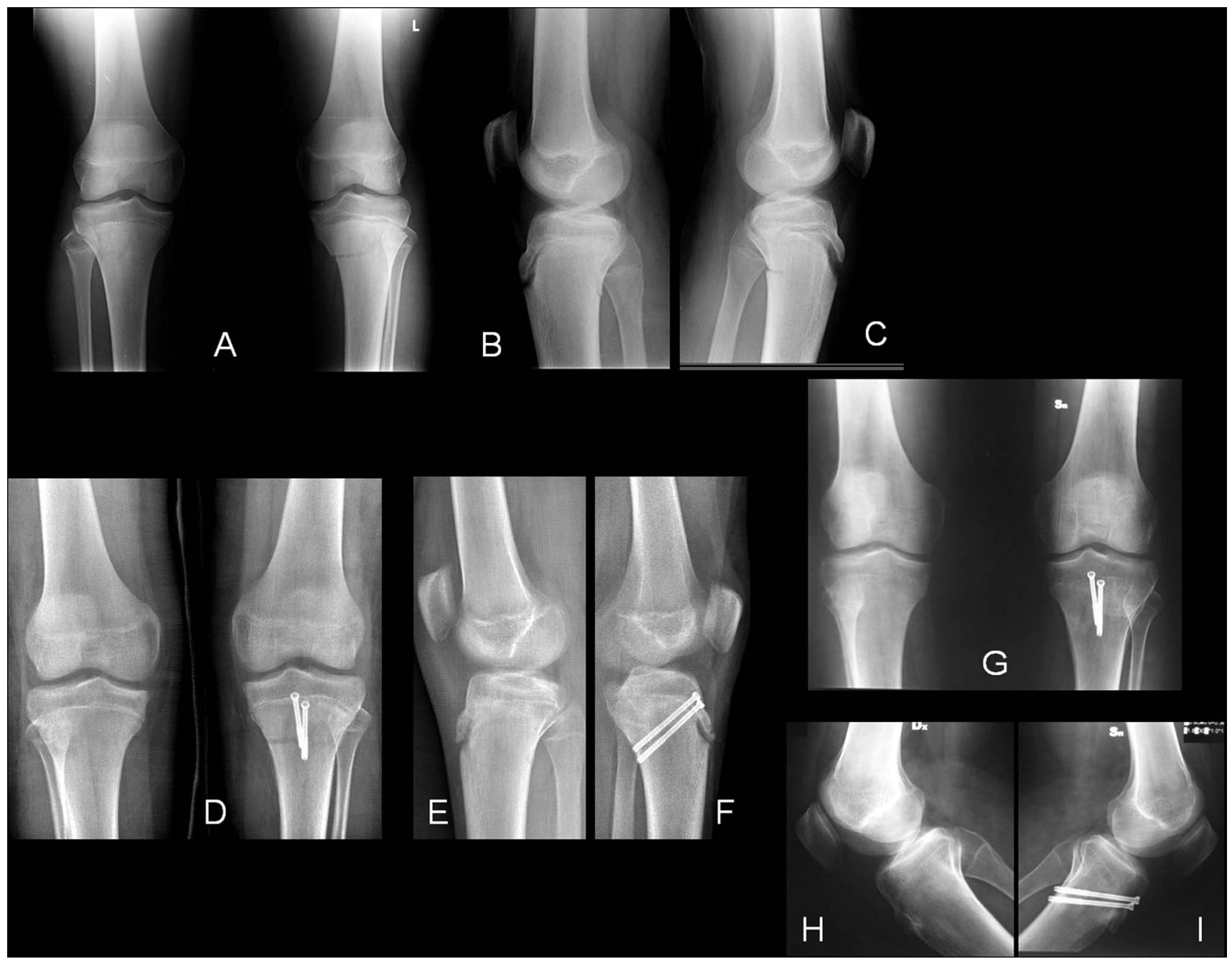

Fig. (1). Radiographic examination of simultaneous bilateral flexion-type Salter-Harris II fractures of the proximal tibia in a 14-year-old boy, non-displaced on the right side and displaced on the left (A-C). The patient was treated conservatively on the right side and surgically, by closed reduction and internal fixation with two cannulated screws, on the left (D-F). At follow-up, one year after the injury, the fractures were perfectly healed, with almost complete fusion of the proximal tibial physes (G-I). The patient had resumed playing basketball without any problem; he refused a second operation to remove the screws.

authors have described a particular flexion-type injury as a combination of a Salter-Harris type II fracture of the proximal tibial physis associated with a tubercle avulsion, and they proposed classifying them as a distinct group of lesions (flexion-avulsion type) [5-7, 15]. This type of physeal separation is more frequent in late adolescence, because the posterior part of the growth plate is usually closed, whereas the anterior part, still open, is vulnerable to this lesion. In fact, the fracture line commonly starts anteriorly along the physis and exits posteriorly through the metaphysis. In flexion-type lesions complications are rare, and no neurovascular injuries have been described in association with this fracture. For non-displaced flexion-type physeal injury of the proximal tibia, conservative treatment is recommended, based on long-leg cast immobilization in extension position for six weeks; the same treatment is indicated for displaced lesions which prove to be stable after closed reduction. For displaced injuries which are unstable after closed reduction, fixation with percutaneous pins or cannulated screws is recommended $[5,15]$.
To the best of our knowledge, only six cases of bilateral physeal injury of the proximal tibia have been reported; in three cases the lesion occurred consecutively (Table 1), whereas in the other three, it occurred simultaneously (Table 2). In none of the cases described previously, classified as Salter-Harris II, were the lesions caused by a flexion trauma bilaterally.

Our patient was a 14-year-old boy in good health, who sustained simultaneous bilateral flexion-type Salter-Harris II fractures of the proximal tibia during a basketball game while landing, with both knees flexed, from a high jump. No previous clinical symptoms of Osgood-Schlatter disease were reported by the patient, and the x-rays taken after the injury did not show any radiographic abnormalities of the anterior tuberosity of the tibia. He was treated conservatively on the non-displaced side and surgically on the contralateral displaced side, by closed reduction and percutaneous fixation with two screws. At follow-up one year after the operation, the patient had returned to playing basketball without any 
Table 1. Literature Review of Cases Affected by Bilateral Physeal Injury of the Proximal Tibia, in which the Lesions Occurred Consecutively

\begin{tabular}{|c|c|c|c|c|c|}
\hline Authors & $\begin{array}{c}\text { Age at } \\
\text { Diagnosis }\end{array}$ & $\begin{array}{c}\text { Severity of } \\
\text { Trauma }\end{array}$ & $\begin{array}{c}\text { Classification } \\
\text { (Salter-Harris) }\end{array}$ & $\begin{array}{c}\text { Interval Between the } \\
\text { Two Injuries }\end{array}$ & Authors' Conclusions \\
\hline \hline Takai et al. [9] & $13 \mathrm{y}$ & Mild & Type I and type II & 6 mo. & $\begin{array}{c}\text { These injuries may occur without a major trauma, } \\
\text { especially in patients with Osgood-Schlatter disease. }\end{array}$ \\
\hline Ozokyay et al. [10] & $14 \mathrm{y}$ & Mild & Type II bilaterally & 4 weeks & $\begin{array}{c}\text { These injuries are rare. If treated properly, } \\
\text { clinical results are good. }\end{array}$ \\
\hline Kraus et al. [11] & $13 \mathrm{y}$ & Mild & Type I and type III & 6 mo. & $\begin{array}{c}\text { Hormonal changes during puberty and loosening of } \\
\text { physeal cartilage are responsible for this type of injury. }\end{array}$ \\
\hline
\end{tabular}

Table 2. Literature Review of Cases Affected by Bilateral Physeal Injury of the Proximal Tibia, in which the Lesions Occurred Simultaneously

\begin{tabular}{|c|c|c|c|c|}
\hline Authors & $\begin{array}{c}\text { Age at } \\
\text { Diagnosis }\end{array}$ & $\begin{array}{c}\text { Severity of } \\
\text { Trauma }\end{array}$ & $\begin{array}{c}\text { Classification } \\
\text { (Salter-Harris) }\end{array}$ & Authors' Conclusions \\
\hline \hline Merloz et al. [12] & $15 \mathrm{y}$ & Mild & Type II bilaterally & $\begin{array}{r}\text { The mechanism of injury is a mild trauma, which often occurs in patients } \\
\text { with Osgood-Schlatter disease. }\end{array}$ \\
\hline Rappold and Vischer [13] & $16 \mathrm{y}$ & Moderate & Type I and type II & Good results with conservative treatment. \\
\hline Kafer et al. [14] & $13 \mathrm{y}$ & Moderate & Type II and type III & $\begin{array}{c}\text { These injuries are rare. The authors illustrate appropriate diagnosis and } \\
\text { treatment of this condition. }\end{array}$ \\
\hline
\end{tabular}

restrictions, and no deformity or leg-length discrepancy were present.

Both the consecutive and the simultaneous injuries previously described, as well as our case, were caused by a minor trauma, and we agree with other authors that the lesion is probably related to less resistance of the growth plate before closure, which is typical during late adolescence. The role of pre-existing Osgood-Schlatter disease in the genesis of this uncommon injury is controversial. Only two of the cases described previously had a positive history for osteochondrosis of the anterior tibial apophysis $[9,12]$. In the remaining four cases, as well as in our case, no clinical or radiographic signs of OsgoodSchlatter disease were present before the injury.

In conclusion, we report the only case of bilateral physeal lesions of the proximal tibia, classified as Salter-Harris type II, which occurred simultaneously with a flexion-type mechanism of injury. We believe that bilateral proximal tibial physeal injuries are extremely rare and they occur with various, age-dependent patterns. The most uncommon pattern is represented by flexion-type lesions, usually classified as Salter-Harris II, which occur in late adolescence when the posterior part of the growth plate is usually closed, whereas the anterior part is still open. The results of treatment are generally good, without any particular complication, since the lesions occur in adolescent patients who are close to growth arrest.

\section{ACKNOWLEDGEMENT}

The authors did not receive any funds for the preparation of this manuscript.

\section{CONFLICT OF INTEREST}

None of the authors has any conflict of interest.

\section{REFERENCES}

[1] Aitken AP. Fractures of the proximal tibial epiphysial cartilage. Clin Orthop Relat Res 1965; 41: 92-7.

[2] Peterson CA, Peterson HA. Analysis of the incidence of injuries to the epiphyseal growth plate. J Trauma 1972;12(4): 275-81.

[3] Burkhart SS, Peterson HA. Fractures of the proximal tibial epiphysis. J Bone Joint Surg Am 1979; 61(7): 996-1002.

[4] Shelton WR, Canale ST. Fractures of the tibia through the proximal tibial epiphyseal cartilage. J Bone Joint Surg Am 1979; 61(2): 16773.

[5] Mubarak SJ, Kim JR, Edmonds EW, et al. Classification of proximal tibial fractures in children. J Child Orthop 2009; 3(3): 191-7.

[6] Ryu RK, Debenham JO. An unusual avulsion fracture of the proximal tibial epiphysis. Case report and proposed addition to the Watson-Jones classification. Clin Orthop Relat Res 1985; 194: 181-4.

[7] Blanks RH, Lester DK, Shaw BA. Flexion-type Salter II fracture of the proximal tibia. Proposed mechanism of injury and two case studies. Clin Orthop Relat Res 1994; 301: 256-9.

[8] Mudgal CS, Popovitz LE, Kasser JR. Flexion-type Salter-Harris I injury of the proximal tibial epiphysis. J Orthop Trauma 2000; 14(4): 302-5.

[9] Takai S, Yoshino N, Kubo Y, et al. Bilateral epiphyseal fractures of the proximal tibia within a six-month interval: a case report. $\mathrm{J}$ Orthop Trauma 2000; 14(8): 585-8.

[10] Ozokyay L, Michler K, Müsgens J. Bilateral atraumatic epiphysiolysis of the head of the tibia. Unfallchirurg 2002; 105(8): 735-9.

[11] Kraus R, Berthold LD, Heiss C, et al. Consecutive bilateral proximal tibial fractures after minor sports trauma. Eur J Pediatr Surg 2009; 19(1): 41-3.

[12] Merloz P, de Cheveigne C, Butel J, et al. Bilateral Salter-Harris type II upper tibial epiphyseal fractures. J Pediatr Orthop 1987; 7(4): 466-7. 
[13] Rappold G, Vischer HM. Bilateral tibial head epiphysiolysis in somersault jumping. Unfallchirurgie 1992; 18(4): 229-32.

[14] Käfer W, Kinzl L, Sarkar MR. Epiphyseal fracture of the proximal tibia: review of the literature and report of simultaneous bilateral fractures in a 13-year-old boy. Unfallchirurg 2008; 111(9): 740-5.
[15] Donahue JP, Brennan JF, Barron OA. Combined physeal/apophyseal fracture of the proximal tibia with anterior angulation from an indirect force: report of 2 cases. Am J Orthop (Belle Mead NJ) 2003; 32(12): 604-7.

(C) Potenza et al.; Licensee Bentham Open.

This is an open access article licensed under the terms of the Creative Commons Attribution Non-Commercial License (http://creativecommons.org/licenses/by-nc/3.0/) which permits unrestricted, non-commercial use, distribution and reproduction in any medium, provided the work is properly cited. 